\title{
Self-perceptions and perceptions of peers: their role in understanding expenditure behaviours
}

\author{
Silvia Emili ${ }^{1} \cdot$ Federica Galli ${ }^{1}$ (D)
}

Accepted: 14 January 2022 / Published online: 4 February 2022

(c) The Author(s) 2022

\begin{abstract}
In the last decades, the analysis of individual consumption behaviours has been enriched by considering several non-rational features of (i) self-perceptions and (ii) perceptions of peers that can affect people's spending decisions, such as subjective well-being and feelings about different aspects of life, as well as measures of social comparison. However, at our knowledge, no studies have yet considered the two sources of emotionality simultaneously. This study aims to investigate the simultaneous role of these two emotional facets in affecting expenditure behaviours of Italian individuals for the year 2016, considering two measures of own satisfaction, relative quantities of SWB and expenditure, and inequality measures. Our results, controlling for potential sources of endogeneity, reveal a significant role of both aspects in influencing individuals' spending habits.
\end{abstract}

Keywords Expenditure behaviours $\cdot$ Subjective well-being $\cdot$ Perception of peers · Inequality $\cdot$ Utility measures

JEL Classification D12 $\cdot \mathrm{I} 31 \cdot \mathrm{P} 46$

\section{Introduction}

For a long time, researchers have considered households and individuals to be rational agents in view of a utilitarian perspective. Conversely, in the last decades, many studies began to look at these agents as emotional people, affected in their economic decisions by feelings, perceptions and subjective well-being (Laros and Steenkamp 2005). The purpose of this study is to address this issue. Indeed, considering this recent and alternative perspective, it is essential for policy makers, national governments and industries to understand how people, and then economic outcomes, are affected by feelings' perceptions and happiness with different aspects of life.

Federica Galli

federica.galli14@unibo.it

Silvia Emili

silvia.emili2@unibo.it

1 Department of Statistical Sciences, University of Bologna, P.tta Teatini 10, 47921 Rimini, Italy 
In the literature of Economic of Happiness, the interest of researchers in understanding how subjective well-being (SWB) influences different life's economic outcomes has increased considerably. One of the motivations behind this new frame of research was found by Lyubomirsky et al. (2005), who observed an increase in happiness levels before and during successful outcome episodes. The empirical evidence of a positive effect of SWB on economic variables has been shown in different frameworks such as personal earnings, productivity, and probability of employment (De Neve, Diener, Tay and Xuereb 2013; De Neve and Oswald 2012; Oswald et al. 2015; Walsh et al. 2018).

In the analysis of individual spending behaviours, Geyskens and Steenkamp (2000), Guven (2012) and Zhu et al. (2020) revealed a significant effect of SWB in affecting consumption expenditures. Specifically, considering Dutch household data, Guven (2012) identifies lower levels of marginal propensity to consume among happier people while Zhu et al. (2020) report an improvement in the expenditures of households living in rural areas through an increase in happiness levels, when these are mediated by income diversification and general enhancements in technology infrastructures. Geyskens and Steenkamp (2000) split SWB into two separate terms: a first one, referring to the immaterial (social and affective) features of life, and a second one, closely related to material aspects (economic conditions). The results of the analysis show that emotionality with economic and social domains largely influences people's consumption decisions.

Aiming at evaluating how economic decisions are affected by feelings, perceptions and subjective well-being, a self-centred point of view may be not sufficient. Economists have long argued that individuals may care about their own income level both in absolute terms and in comparison with others (Clark and Oswald 1996; Luttmer 2005; Solnick and Hemenway 2005). Then, beside the meaningful role given by individuals to self-reported SWB, we consider the comparison with peers as a second aspect related to households and individuals' non-rationality, generating changes in decision patterns. As pointed out by Foy et al. (2014), while authors usually concentrate on the material aspects of social comparison, the emotional outcomes of inequality are a relevant and meaningful topic as well in the analysis of individual behaviours. Indeed, "people who occupy the lower positions in unequal social structures experience negative, impotent, and unengaged feelings that depress their quality of life" (Foy et al. 2014, p. 295).

As underlined by Aristotle, "Man is by nature a social animal; an individual who is unsocial naturally and not accidentally is either beneath our notice or more than human". More recently, the prospect theory postulated that individual utility measured as level of satisfaction may be influenced by social comparison due to the natural reference point represented by peers (Tversky and Kahneman 1991). In the literature on subjective well-being, individuals appear to be more psychologically satisfied when they feel to overcome the others (Clark, Frijters, and Shields 2008), deriving positive utility from status tied to their rank in the distribution of expenditure, income, or similar measures of well-being.

In the analysis of consumption behaviours, the empirical evidence show that individuals' utility is strongly affected in some way (positively or negatively) by average levels of others and inequalities among individuals belonging to the same relevant reference group. Therefore, individual expenditures come out to be intertwined with the spending habits of others (Harriger-Lin et al. 2020). Referring to the analysis of conspicuous consumption, it can be argued that it exists a significant relationship between expenditure of individuals and average levels, as well as inequality, about the reference group. Despite the general agreement in the literature about this nexus, a general consensus on the magnitudes and signs of the impact of the comparison with peers on individual utility measures has not yet been achieved. 
Nevertheless, despite the relevance of different sources of emotionality in the analysis of individuals spending habits, at our knowledge no studies have yet considered perceived self-reported satisfaction levels and perceptions of others simultaneously. Therefore, the main aim of the paper is to test the hypothesis that:

H1 Individual expenditures will be affected not only by the typical individual characteristics (like age, family status etc.) but also by the feeling of own well-being and by perception of others.

In order to test this hypothesis, using data on Italian individual expenditures and satisfaction for the year 2016, we combine various life satisfaction scores to construct two measures of well-being: one related to the satisfaction with economic conditions and the other with the satisfaction with the social sphere. In addition to these two measures, we also take account of utility experienced by the reference group in a twofold reading: average levels and inequality.

Moreover, we further test the possibility that:

H2 One or more utility measures related to peers can affect individual consumption behaviour.

Following Attanasio and Pistaferri (2016), and in contrast with most economists and statisticians who refer to income to depict inequality, we evaluate perceptions of peers focusing on two of the most meaningful aspects detecting individuals' utility, i.e. consumption and satisfaction, as the final goals of people's lives.

In sum, at our knowledge, this is the first paper that investigates the simultaneous role of self-perceptions (measured by satisfaction with economic conditions and satisfaction with the social sphere) and perceptions of peers (using average levels and inequality measures) in affecting expenditure behaviours. Moreover, the second novelty of the paper concerns the possibility that both consumption and satisfaction related to peers can affect individual spending behaviour, allowing to disentangle the economic and social facets of social comparison.

The results of the analysis, controlling for endogeneity using two stage least square estimation procedure, show the meaningful role of both satisfaction metrics and perceived disparities in influencing the spending behaviour of individuals. In particular, the two satisfaction variables and peers' expenditure have a positive impact on individual spending levels. At the same time, individuals appear to be not influenced by the SWB level of peers, while they consider satisfaction inequality as a negative meaningful determinant of expenditures.

Empirical findings from this work can lead to several economic implications. In particular, policy makers should mainly concentrate on the positive effect of self-reported SWB and on the negative impact of SWB inequality on expenditure. These insights suggest the relevance of developing place-based programs (Bernini and Tampieri 2019; 2020) to improve the overall satisfaction level of citizens and to mitigate SWB disparities due to their negative impact on people spending decisions. 


\section{Satisfaction as predictor of individual expenditures}

The relationship between subjective and material well-being is of primary interest in the Economics of Happiness literature, with empirical investigations mainly focused on the effect of economic variables such as unemployment, inflation, income and consumption on happiness (Carver and Grimes 2019; Clark 2017, 2018; Diener et al. 2015; DeLeire and Kalil 2010; Reyes- García et al. 2019; Yeniaras et al. 2016; Verme 2011).

Recently, the reverse effect is receiving increasing attention (Kahneman and Krueger 2006; Guven 2012), which is partly due to the empirical evidence of the effect of SWB on successful economic outcomes. Taking income into consideration, Graham et al. (2004) found that positive expectations and happiness positively affect income levels in future periods. Likewise, in the longitudinal analysis of family incomes in the US, De Neve and Oswald (2012) provided insights on the causal relationship between wellbeing and income. Their analysis suggests that people showing high levels of happiness experience a significant increase in earnings many years later. Focusing on financial activities and investment preferences, Guven (2011) and Schoemaker (1993) demonstrated relevant differences in risk aversion, distinguishing between happy and unhappy people. In labour market analysis, starting from the fundamental work of Boehm and Lyubomirsky (2008), Walsh et al. (2018) found that happiness comes before success in several cases, considering cross-sectional, longitudinal and experimental data, thereby contributing to an increase in consumption (Graham et al. 2004). De Neve et al. (2013) found that subjective well-being affects individual future self-re-employment and reentry wages, while Krause (2013) observed that a moderate degree of satisfaction is beneficial to success in business and in life as a whole. Moreover, happy people are more trustful, they tend to participate more in social activities and expand their social network, which may lead them to spend more on gifts (Guven 2011). Referring to expenditures, Zhu et al. (2020) and Guven (2012) have analysed the impact of happiness on consumption levels. The former, using Chinese data, found that higher levels of happiness are associated with an increase in expenditure, while the latter, using the Dutch Household Survey, found that happier people have a lower marginal propensity to consume. Geyskens and Steenkamp (2000) split SWB into social and economic well-being, showing that emotionality with both domains significantly affect people's consumption decisions.

\section{Perceptions of others}

Starting from early 1900 economists became more and more aware that a deep and comprehensive understanding of market behaviour is not possible without considering the psychological and social aspects that characterise households and individuals' decision processes. Moreover, in the following years, they increasingly acknowledged the relevance of socially-stimulated decisions on consumer demand analysis, as well as the importance of interpersonal effects (Tilman 1992). Focusing on the tendency to consume for status, Veblen generalized and simplified the analysis of socially-complex consumption phenomena (Bronner 1989) and limited his description primarily to ostentatious and visible consumption actions. Sumarwan (2011) found that the consumer purchasing decision process is influenced by individual and environmental differences. In particular, these last refer to the association of several individual characteristics with factors related to reference groups, 
environment, and conditions of peers. Although this largely documented systematic correlation between relative economic measures and self-reported satisfaction scores, the heterogeneity and the interpretation of the empirical findings seems to be not always straightforward, and sometimes contradictory. Relative effects still represent a daunting challenge in consumption behaviour analysis, due to the issue of credibly identifying what is perceived by others, of defining what a proper reference norm is, and what visible and invisible features of peers are, in the current social and digital era.

Beside the distance from a specific reference group, inequality is one of the most investigated determinants of utility, generating quite controversial results in empirical studies, including negative effects (e.g. Alesina et al. 2004; Blanchflower and Oswald 2003; Graham and Felton 2006; Verme 2011), weak relationship (e.g. Di Tella and MacCulloch 2008; Reyes- García et al. 2019; Tavor et al. 2018) and positive effects (Clark 2003). However, the general idea is that inequality is not only associated to material aspects, but it can be also considered as a source of negative emotional features such as powerlessness, depression, and stress (Foy et al. 2014).

In recent years, interesting extensions related to income inequality perceptions have been provided by the literature on which aspects are perceived by people as inequal. In this sense, consumption inequality (Aguiar and Bils 2015; Meyer and Sullivan 2013; Heathcote et al. 2010) and satisfaction inequality (Van Praag and Ferrer-i-Carbonell 2011) started receiving growing attention, due to the substantial differences observed in terms of income-based inequalities.

Taking into consideration happiness inequalities, Veenhoven (1990) found that countries characterised by small income differences, major development, equal education chances and higher social security show a more equal happiness distribution. Lam and Liu (2014) for China, Okulicz-Kozaryn and Mazelis (2017) for the USA and Graafland and Lous (2019) for 25 OECD countries, demonstrated the association between socio-economic and happiness inequalities.

Researchers also concentrated on examining how consumption inequalities influences people's spending decisions, finding different and controversial results. In particular, Roychowdhury (2017) and Chai et al. (2019) found that an increase in peer group inequality reduces conspicuous consumption expenditure for Indian and South African households, respectively. On the contrary, Harringer-Lin et al. (2020), using U.S. survey data, demonstrated a positive association between expenditure inequality and household's expenditure share in clothing, jewellery, personal care, vehicles, alcohol, and tobacco and a negative association for the expenditure categories of healthcare, utilities, vehicle maintenance, home furnishings, and charitable donations. Specifically, they underlined that people's reaction to increased expenditure inequality can lead either to emulative behaviours or to the desire to be different from others.

In this paper we investigate the possibility that the living conditions of peers can influence people's expenditure as a result of comparisons with others. More specifically, we consider two different sources of emotionality related to average values and inequalities: consumption expenditure and happiness with overall life. 


\section{Model and variables}

In this study, we model individual expenditure as a function of happiness, average measurements among the reference group, perceived inequalities, and several control variables. The model is formally given by:

$$
\text { Expenditure }_{i}=f\left(\text { Happiness }_{i}, \text { Reference }_{i}, \text { Inequality }_{i}, \text { Controls }_{i}\right) .
$$

As first pointed out by Guven (2012), and then by Zhu et al. (2020), the reversal specification of the satisfaction-consumption function defined by Eq. 1 is not so common in literature. The main components of the equation are represented by the economic outcomes, here identified by individual equivalent expenditure, Expenditure ${ }_{i}$; the SWB scores, given by Happiness $s_{i}$, a set of average measurements characterising the reference group (identified by Reference $_{i}$ ); variables measuring perceived inequalities (i.e. Inequality ${ }_{i}$ ) and a set of controls for individual, household and contextual characteristics (i.e. Controls $s_{i}$ ). As underlined by Guven $(2011,2012)$ and Zhu et al. (2020), Eq. 1 could imply possible endogenous relationships. Therefore, aiming to control for endogeneity, we use a two stage least square estimator (2SLS) to perform our analysis, as described in the following sections.

Individual Expenditures and Subjective Well-being. Carver and Grimes (2019) depicted the dualism of income and consumption-based measures in defining material well-being. Despite the centenarian interest and the efforts of policy makers to improve classical measures of production and income, e.g. Gross Domestic Product, the authors examined the ability of surveyed income and consumption-based quantities to predict household utility, as defined by SWB measures. Guillen-Royo (2008) suggested how the use of consumption data can reveal fundamental aspects such as materialism, modern hedonism and social comparison.

In this paper, we measure individual equivalent expenditure, excluding unusual expenses, as household monthly expenditures, transformed in individual expenses by using the Carbonaro (1985) equivalence scale. Specifically, these amounts are obtained by using specific equivalence coefficients (related to family size) to equally share the total household's expenditure among the household's components. Indeed, when total consumption expenditures are investigated, the equal sharing represents the most useful transformation, since relevant expenses impact the whole household budget (among others, food, dwelling expenses and services) and concern all the family members.

Referring to subjective well-being, many studies have shown supporting evidence about surveyed life satisfaction scores as meaningful metrics of individual well-being (Helliwell et al. 2013). Empirical investigations mostly refer to self-reported values, collected as survey data, that measure satisfaction with overall life on a scale from 0 to 10 (Clark 2018). Usually, implications related to satisfaction with life domains are derived considering the estimates associated with status variables (e.g. being married, as a positive condition in social well-being, having a high-status job as positive aspect of job satisfaction), without considering the subjective evaluation of different dimensions of life. Decancq et al. (2015) depicted the relevance of the different aspects of life, such as health status, social relationships, job-related variables and environmental aspects in understanding individual overall happiness. Likewise, Easterlin and Sawangfa (2007) focused on the satisfaction scores of people taking four life domains into consideration: finance, family life, work and health.

In this paper, we assume that overall satisfaction is the result of several life domain scores, separable in two different dimensions: the social component and the economic 
counterpart. The corresponding measures of satisfaction are derived considering the two terms as latent constructs of several domains of subjective well-being.

Relative measures and Reference norm. The comparison of own individual utility levels with respect to peers represents a fundamental aspect in this framework (Stephany 2017; Reyes-García et al. 2019). In the model proposed for this analysis, we include relative measures of SWB and expenditures, to control for the effect of the comparison with peers on spending behaviours (Attanasio and Pistaferri 2016; Heathcote et al. 2010; Van Praag and Ferrer-i-Carbonell 2011). An adequate identification of the reference group, with respect to objectives and geographic and temporal context, becomes fundamental. The need for a finer spatial detail of reference is evidenced by Oshio and Kobayashi (2011), who depict a relevant difference in the sensitivity of individuals to inequalities in relation to several features. In line with the famous idiom of the English-speaking world, the keeping-up-with-the-Joneses effect, the authors slightly improve the spatial detail in measuring inequalities, moving from the national to the prefectural level. Brodeur and Fleche (2019) increase the geographic detail of investigation (to the limit) considering the ZIP code level. People compare themselves and their economic and social conditions to neighbours, friends, and family members, and not to reference groups such as "compatriots" or "not personally-related" individuals (Graafland and Lous 2019). Nonetheless, in a social and digital era, referring solely to a narrow group of people, in geographical proximity and close in affection terms, could appear limiting and misleading.

In this work, the reference norm is obtained distinguishing between two main features identified by regional disparities (Capello 2016; Giarda and Moroni 2018; Lenzi and Perucca 2018; Odoardi and Muratore 2018), here represented by regions and urbanisation level, and a specific individual characteristic given by age classes. Indeed, "Age inequalities occur throughout the whole age structure" and "they occur because age is used as a criterion for assigning people to roles that are differentially rewarded" (Foner 1988, pp. 178). Age systematically shapes access to resources and life opportunities, and it is a source of inequality "because social relations associated with it potentially led to long-lasting systematic differences in social opportunities and rewards" (Western and Tomaszewski 2016). The role of this variable is central in characterising both SWB, as a well-known U-shape function (Helliwell 2003; Blanchflower and Oswald 2008), and the level and the composition of expenditures, as varying along the life cycle (Blundell et al. 1994; Fernadez-Villaverde and Krueger 2007).

Control variables. Following the Economic of Happiness literature, several individual characteristics are included in the regression analysis. In detail, the set of control variables considered in the specification is given by age, gender, education, marital status, urbanisation, macro-areas and the conditions of belonging to alternative, sensitive and vulnerable categories of population: being poor, unemployed and retired.

\section{The data}

The dataset has been built for 2016 considering two different Italian surveys, both developed by the Italian Office of Statistics (ISTAT): the first, Aspect of Daily Life (ADL), collects data about households' and individuals' living conditions, with a specific focus on satisfaction scores about overall life and several life domains, whereas the second, Household Budget Survey (HBS), quantifies the monthly expenditure habits of Italian households at a fine detail of spending aggregates. The two surveys are combined through the use of 
common variables contained in the two datasets (D'Orazio et al. 2006), finally obtaining a synthetic file that provides information about 23,002 Italian citizens for 2016. For a review of similar solutions and empirical applications see Ridder and Moffitt (2007) and references therein. Further details, coherence indicators and descriptive statistics for the final dataset are shown in Appendix 1.

As previously described, a strong point of the ADL survey is represented by the availability of several satisfaction scores about different aspects of life. To use this multidimensional nature in full, we consider two main classes of well-being, representative of perceived satisfaction with the economic conditions and with the social sphere. The two classes introduced in the model are obtained starting from six specific satisfaction scores, measured on a 1-4 scale: relationship with friends (Friends), economic condition (EconomicC), health status (Health), happiness related to leisure time (FreeTime), evaluation of available income in relation to needs (AvailableInc) and evaluation of the current family economic condition compared to that of the previous year (PreviousInc, measured on a 1-5 scale, unlike the other variables). To summarise the information about the six domains, we extracted the two SWB measures through a factor analysis on the polychoric covariance matrix for the considered satisfaction scores (further methodological details on factor analysis are included in Appendix 2). The analysis of the factor loadings reported in Appendix 2 shows a first factor strongly associated to economic aspects (i.e. EconomicC, PreviousInc, AvailableInc) and a second one closely related to the social sphere of life (i.e. Health, FreeTime, Friends). Henceforth, we refer to these two factors as EconSatisf and SocSatisf, respectively.

Table 1 contains some descriptive statistics for the six life domains satisfactions (identified in the Table by Social Sphere and Economic Sphere), the two variables extracted through the factor analysis (SWB Factors) and the two instruments (Istruments), i.e. presence of green areas in the neighbourhoods (GreenAreas) and accesses to health care facilities (Hospitalization). A detailed discussion about the choice of the two instruments is reported in the following sections. Finally, in the last two rows on Table 1 we report some statistics about the two utility variables used to measure peers' perceptions, i.e. overall life satisfaction scores and total expenditure. Following the definition used to identify the reference groups, we distinguish between four age classes (defined by Young as people aged 18-29; Middle-Aged as 30-44; Adult as 45-59 and Senior as over-60 people), three urbanisation levels (Metropolis, ${ }^{1}$ as identified by ISTAT (2015), Urban as residence areas with more than 50,000 inhabitants, and Rural as areas with less than 50,000 inhabitants), and three Italian geographic macro areas (North, Centre and South and Islands, for brevity South).

Concentrating on the different age classes, EconSatisf reports higher values for seniors (1.65) and lower levels for adults (1.58), while SocSatisf tends to decrease with ages, reflecting the pattern of the variables corresponding with these two aspects of life. Specifically, the oldest individuals experience lower levels of AvailableInc and PreviousInc but they are the most satisfied with their economic condition, while Middle-Aged and Adult are the least satisfied with their economic status. Moreover, satisfaction with the relationship with relatives and with the leisure time is higher for young people and seniors, while satisfaction with friendships and health tends to decrease with age. Referring to satisfaction

\footnotetext{
1 ISTAT identifies as Metropolis the 12 largest cities of Italy (Torino, Milano, Venezia, Genova, Bologna, Firenze, Roma, Napoli, Bari, Palermo, Catania, Cagliari) balancing physical and administrative characteristics.
} 


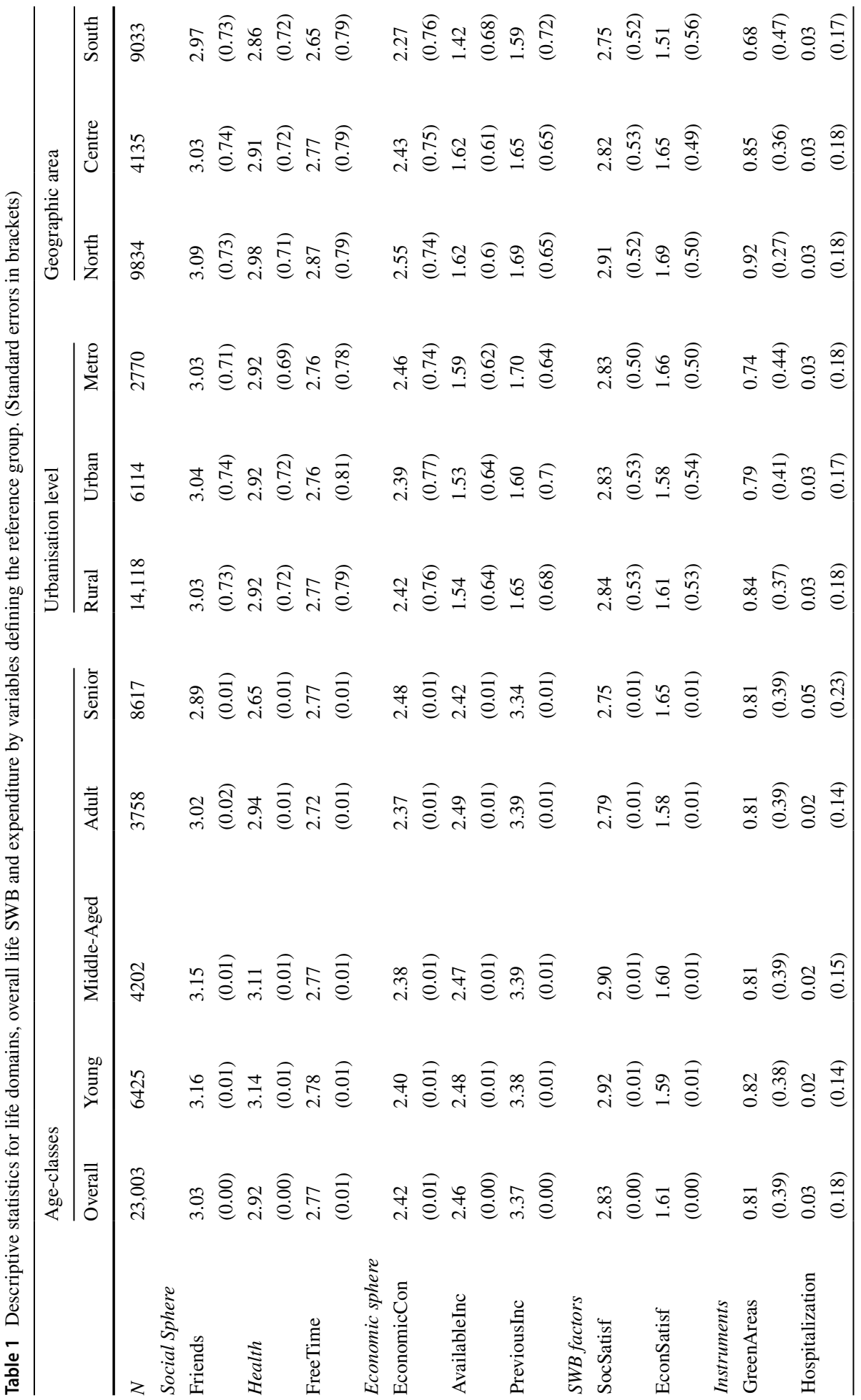




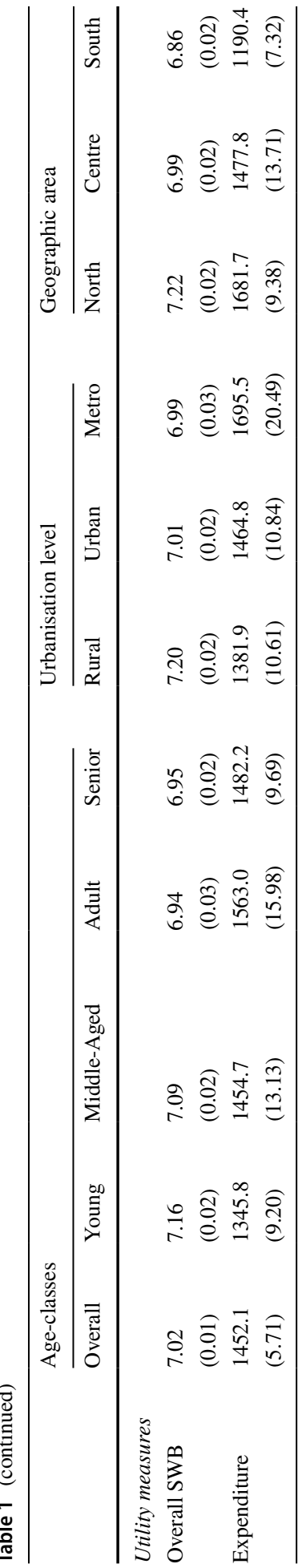




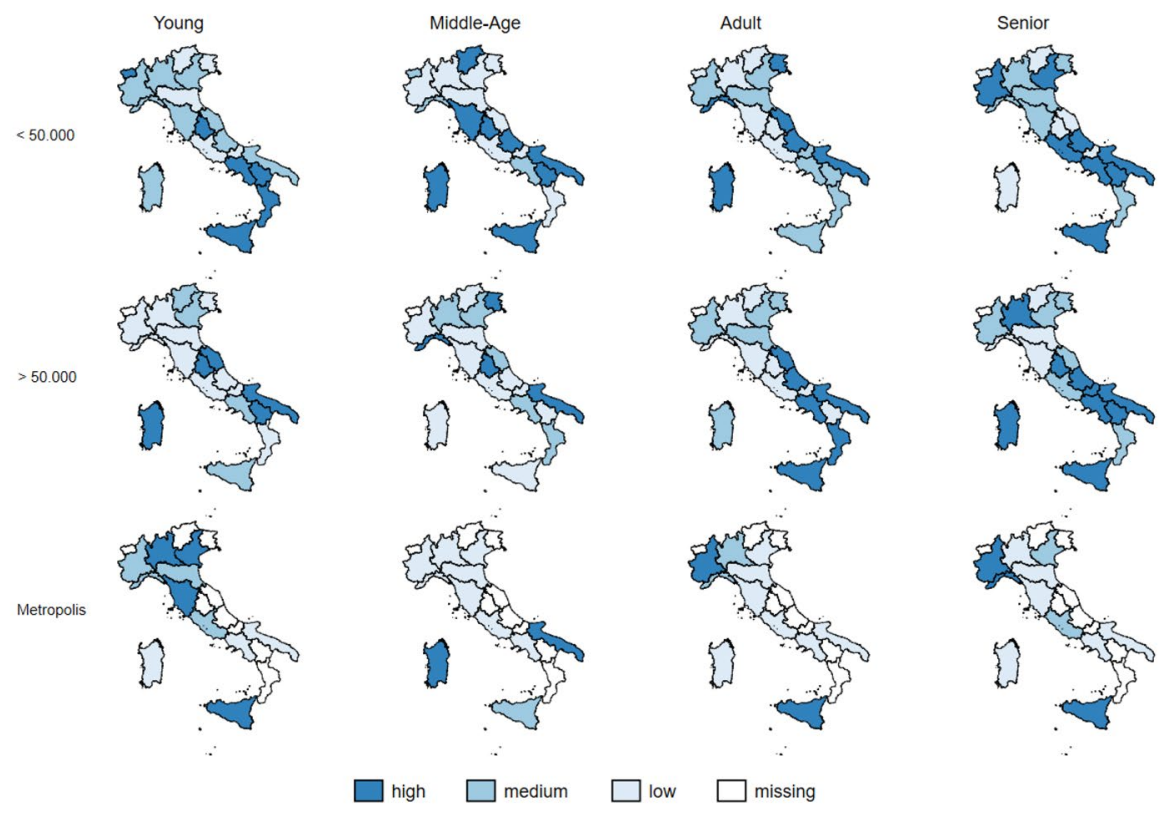

Fig. 1 Well-being inequalities across regions

with relatives, economic condition and leisure time, adults are, on average, the least satisfied compared to the other age classes.

Focusing on the degree of urbanisation, EconSatisf reports higher values for people living in metropolis (1.66) while people living in urban areas are the least satisfied with their economic condition (1.58), reflecting the pattern of the variables concerning the economic sphere. Conversely, there are not substantial differences across the three urbanisation levels regarding the social sphere, reporting fairly constant scores across the three areas.

Finally, people living in the North of Italy are the most satisfied both for the economic aspects of life and for the social ones (EconSatisf and SocSatisf are equal on average to 1.69 and 2.91, respectively), while people living in the South of Italy are the least satisfied overall (EconSatisf and SocSatisf are 1.51 and 2.75 on average, respectively). In particular, all the variables considered in the analysis follow this pattern across the three Italian macro areas.

Referring to perceptions of others, in the last two rows of Table 1, we report some insights about the behavioural heterogeneity of overall life satisfaction scores and expenditure. This suggests the need to consider in the investigation relative measures for peers' utility, combining the three variables identified to build the reference groups. Moreover, we calculate the Gini index on total individual expenditure to measure spending inequality, while, to obtain a measure of satisfaction-perceived disparities it is necessary to use a suitable metric that takes the categorical nature of the SWB variable into account. Thus, starting from overall life satisfaction scores, measured by ADL as 0-10 scale variables, we consider a Gini impurity index to define SWB inequality (Kalmijn and Veenhoven 2005). 

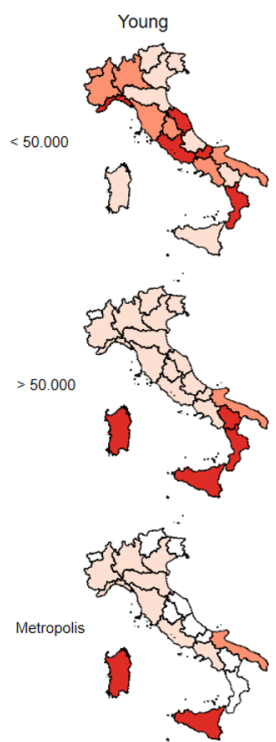
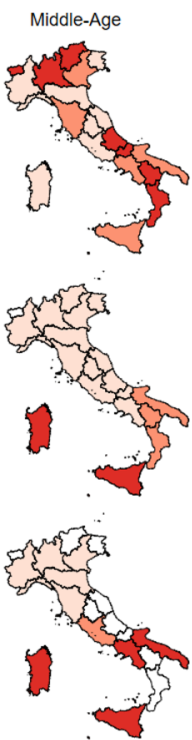

high
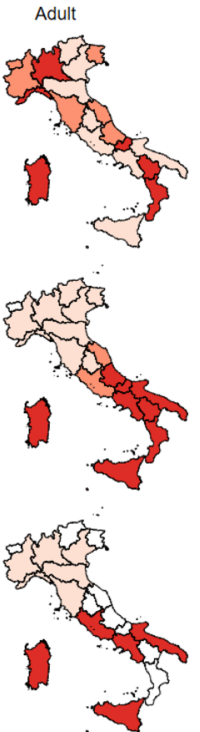

missing

Fig. 2 Consumption expenditure inequalities across regions

In line with the three variables used to identify the reference norm, Fig. 1 shows the distribution of well-being inequality across the 20 Italian regions, directly differentiating for the level of urbanisation and age classes. Moving from the upper-left panel to the lowerright one, in rural and urban areas, well-being inequality is particularly evident in the Centre-South of Italy and it tends to increase at increasing ages, with some exceptions. Conversely, well-being inequalities in metropolitan areas are more evident for younger people living in Northern Italy and in Sicily.

The distribution of expenditure inequality is given in Fig. 2. Individuals living in the urban areas and in metropolises of Central and Southern Italy experience higher levels of consumption inequality compared to people living in the North.

Moreover, in these areas, the magnitude of expenditure inequality increases with age. Concentrating on rural areas, disparities seem to be less evident across the Italian territory, even if seniors continue exhibiting higher inequality levels.

\section{Empirical specification}

Starting from Eq. 1 the empirical model is given by: 


$$
\begin{aligned}
& \ln \left(\text { Expenditure }_{i}\right)=\alpha+\underbrace{\ln \left(\text { EconSatisf }_{i}\right) \varphi_{1}+\ln \left(\text { SocSatisf }_{i}\right) \varphi_{2}}_{\text {Ownperception }} \\
& +\underbrace{\text { Satisf_Ref } \delta_{i}+\text { Satisf_Ineq }_{i} \theta_{1}}_{\text {Perceptionofpeers_Social }}+\underbrace{\text { Econ_Ref } \delta_{i}+\text { Econ_Ineq }_{i} \theta_{2}}_{\text {Perceptionofpeers_Economic }}+\boldsymbol{X}_{i} \boldsymbol{\beta}+\varepsilon_{i}
\end{aligned}
$$

where $\ln \left(\right.$ EconSatisf $\left._{i}\right)$ and $\ln \left(\right.$ SocSatisf $\left._{i}\right)$ are the logarithm of the two factors used to proxy satisfaction with the economic condition and with the social sphere respectively, for individual $i=1, \ldots, N$, and with $\varphi_{1}$ and $\varphi_{2}$ representing the related expenditure elasticities; Satisf_Ref ${ }_{i}$ and Econ_Ref ${ }_{i}$ are obtained as the average of own overall life satisfaction score and expenditure level observed for the individual specific reference norm, each time excluding the ith observation; Satisf_Ineq $q_{i}$ and Econ_Ineq $q_{i}$ are well-being and expenditure inequality, calculated as Gini impurity index and Gini index, respectively. $\boldsymbol{X}_{i}$ refers to the set of socio-demographic characteristics defined by: the dummy variable Gender (with male used as reference group); three dummy variables Young, Middle-Aged and Senior (Adult identified as baseline); the dummy variables HighEdu identifying individuals with highest level of education (academic and higher degrees); the set of dummies Married, Divorced and Widowed respectively identifying individuals that are married or in stable relationship, divorced and separated people, and widowed (singles are used as reference group); to capture economic vulnerable conditions we include the dummies Unemployed and Retired (the first representing both individuals that are looking for first employment and unemployed, and the second variable for retired people), and the dummy Poor for people reporting an equivalent expenditure amount below the Italian poverty line; the dummy variables Rural and Metropolis refer to the different urbanised areas of Italy (where Urban is the baseline) and finally, North and South are two dummies for Italian geographic macroareas (with Centre used as reference group).

As pointed out by Guven (2012), Zhu et al. (2020) and Bernini et al. (2021), individual satisfaction can be a potential source of endogeneity in the analysis of consumption behaviour of people. To take into account this specific issue in the estimation of Eq. 2, a twostage least square (2SLS) procedure is considered (Krause et al. 2013; Zhu et al. 2020). The approach is organized as follows: in a first step the two endogenous variables (i.e. the two scores of satisfaction) are regressed on the set of controls and on the two corresponding instruments; then, in the second step, the estimated residuals obtained in the first stage are included in the investigation of the outcome variable (i.e. individual expenditures), keeping constant the set of controls. In this analysis we consider as instruments the presence of green areas in the neighbourhood of individual residence, and accesses to health care facilities, capturing individuals' health condition. Considering green areas, since environmental conditions of living residence are related to external factors, in practice, they can theoretically and empirically be considered as relevant and exogenous sources of variance in explaining individual expenditure habits. Moreover, recently, the attention of researchers in evaluating the importance and complexity of the nexus between well-being and the natural environment dimension has strongly increased, finding evidence of a relevant association between these two dimensions (Helne and Hirvilammi 2015; Hopwood et al. 2005; Mace 2014). On the other hand, we can imagine that even if individuals are unsatisfied by the living environment in which their household lives, the absence of green areas in the closest surrounding territory should not impact the level of expenditure in the cross-sectional observation of individual spending. 
Table 2 Nested Models

\begin{tabular}{|c|c|c|c|c|c|}
\hline Ln_Expenditure & M1 & M2 & M3 & M4 & M5 \\
\hline Ln(EconSatisf) & $1.06 * * *$ & - & - & - & $1.05 * * *$ \\
\hline Ln(SocSatisf) & $0.33 *$ & - & - & - & $0.35^{*}$ \\
\hline Econ_Ref & - & $0.60 * * *$ & - & $0.61 * * *$ & $0.59 * * *$ \\
\hline Satisf_Ref & - & - & 0.02 & 0.26 & 0.08 \\
\hline Econ_Ineq & - & $0.28 * * *$ & - & $0.36 * * *$ & $0.36 * * *$ \\
\hline Satisf_Ineq & - & - & $-0.72 * * *$ & $-0.81 * * *$ & $-0.67 * * *$ \\
\hline Res_Ln(EconSatisf) & $-0.94 * * *$ & - & - & - & $-0.93 * * *$ \\
\hline Res_Ln(SocSatisf) & -0.29 & - & - & - & -0.30 \\
\hline Young & $-0.12 * * *$ & -0.00 & $-0.07 * * *$ & -0.01 & $-0.06 * * *$ \\
\hline Middle-Aged & $-0.09 * * *$ & $-0.03 * * *$ & $-0.06 * * *$ & $-0.05 * * *$ & $-0.08 * * *$ \\
\hline Senior & $-0.10^{* * * *}$ & $-0.05^{* * *}$ & $-0.05^{* * *}$ & $-0.04 * * *$ & $-0.09 * * *$ \\
\hline Gender & $-0.04 * * *$ & $-0.03 * * *$ & $-0.03 * * *$ & $-0.03 * * *$ & $-0.04 * * *$ \\
\hline HighEdu & $0.06^{* *}$ & $0.23 * * *$ & $0.24 * * *$ & $0.23 * * *$ & $0.06^{* *}$ \\
\hline Married & -0.02 & 0.01 & 0.01 & 0.01 & -0.02 \\
\hline Divorced & $0.23 * * *$ & $0.07 * * *$ & $0.08 * * *$ & $0.07 * * *$ & $0.23 * * *$ \\
\hline Widowed & $0.05 * * *$ & $-0.03 * *$ & $-0.03 * *$ & $-0.03 * *$ & $0.05^{* * *}$ \\
\hline Unemployed & $-0.07 * *$ & $-0.15^{* * *}$ & $-0.15^{* * *}$ & $-0.15 * * *$ & $-0.07 * *$ \\
\hline Retired & $0.02 *$ & $0.06^{* * *}$ & $0.06 * * *$ & $0.06 * * *$ & $0.02 * *$ \\
\hline Poor & $-0.55 * * *$ & $-0.97 * * *$ & $-0.96 * * *$ & $-0.96^{* * *} *$ & $-0.55 * * *$ \\
\hline North & $0.10 * * *$ & $0.03 * *$ & $0.12 * * *$ & $0.03 * *$ & $0.12 *$ \\
\hline South & 0.01 & $0.03 * *$ & $-0.08 * * *$ & $-0.05 * *$ & $0.04 * * *$ \\
\hline Rural & $-0.06 * * *$ & 0.00 & $-0.02 * * *$ & 0.01 & $-0.03 * * *$ \\
\hline Metropolis & $0.03 * * *$ & $0.02 * *$ & $0.09 * * *$ & $0.02 * *$ & $0.03 * *$ \\
\hline Constant & $6.50 * * *$ & $2.84 * * *$ & $7.76 * * *$ & $2.87 * * *$ & $2.51 * * *$ \\
\hline
\end{tabular}

$(* * *: p$-value $\leq 0.01 ; * *: \leq 0.05 ; *: \leq 0.1)$

As for the access to health care facilities (e.g. hospitals and medical centre), one could argue that, other things equal, it exists a positive association between health status and satisfaction. Indeed, poor health conditions can lead to bad feelings such as distress from unfamiliar surroundings and scare of the unknown, negatively affecting the level of perceived life satisfaction of individuals (De Prophetis et al. 2020). On the other hand, the main characteristic of the Italian health system is represented by mixed public and private services and structures, guaranteeing free hospital admissions, several specialist consultations, lab analyses, and diagnostic procedures. Thus, it can be assumed that economic outcomes are not affected by the need of being hospitalized.

\section{Results and discussion}

The results of the estimation are collected in Table 2. In particular, M1 includes the estimates obtained starting from Eq. 2, only considering own perception measures, EconSatisf and SocSatisf, and residuals coming from first stage of 2SLS procedure (see APPENDIX 
3 for the first stage estimated models), Res_Ln(EconSatisf) and Res_Ln(SocSatisf); in M2 and M3 we investigate the effect of perception of peers separating the two dimensions of utility (Econ_Ref and Econ_Ineq in M2, and Satisf_Ref and Satisf_Ineq in M3). Finally, M4 represents the overall model for the inclusion of all metrics regarding perceptions of others, and M5 concerns the comprehensive model specified in Eq. 2.

We evaluate emotionality in individual consumption decisions firstly as the effect of perceived own well-being level on individual expenditure. Specifically, the coefficients associated with EconSatisf and SocSatisf, representing the expenditure elasticities of the two SWB dimensions are positive and significant both in M1 (1.06 and 0.34, respectively), where they represent the only source of feelings, and in the overall specification of M5 (1.05 and 0.35) where all perceptions are considered. Next, we evaluate the effect related to the comparison with peers on people's consumption behaviour. The coefficients related to perceived expenditure disparities show a positive and significant effect in M2, M4 and M5, both for Econ_Ref (0.60 in M2, 0.61 in M4 and 0.59 in M5) and for Econ_Ineq (0.28 in M2, 0.36 in M4 and 0.36 in M5). Conversely, SWB disparities negatively influences individual spending only through the inequality index. Indeed, the coefficient associated with Satisf_Ineq is negative and significant in M3 (-0.72), in M4 (-0.81) and in M5 (-0.67), while the coefficient associated to Satisf_Ref is not significant in all the three models.

Considering our first hypothesis H1, M5 confirms that expenditure behaviours of individuals are related both to own well-being perceptions and by perception of others. The estimates obtained in the last four nested models show the importance of distinguishing between the two utility dimensions due to their significant and opposite role in affecting individual consumption behaviours. These findings depict the relevance of both utility metrics here considered to take perceived conditions of peers into account.

In line with the arguments proposed by Zhu et al. (2020) for the impact of overall life satisfaction on expenditure, individuals reporting higher levels of satisfaction with their economic condition, having adequate economic availability, are more willing to spend money, generating higher levels of consumption expenditure. Concentrating on SocSatisf, people who are more satisfied with their relationship with family, with leisure time and health are motivated and encouraged to spend more money in social activities and events, to meet people and to consume, participating "more in community events, social gatherings, cultural events, local politics and religious events" (Guven 2011).

To validate the second research hypothesis $\mathrm{H} 2$, we distinguish between economic and social features related to peers that can affect individual consumption behaviour.

Focusing on the economic aspects, the positive coefficients of Econ_Ref and Econ_Ineq, demonstrate a high level of sensitivity of individuals to perceived disparities in spending habits. According to the theory of conspicuous consumptions (Veblen 1899), spending is driven by status-related considerations and the richest people represent the standard to reach. As a consequence, individuals tend to raise their own consumption levels, displaying ostentatious wealth to gain status and reputation in society (Bowles and Park 2005). Thus, individuals' consumption levels increase at increasing consumption inequalities because people try to emulate the living standard of the richer. On the other hand, considering the social component of $\mathrm{H} 2$, the estimates associated with perceptions of peer's well-being show that only SWB inequalities among peers negatively affects individual consumption expenditure. This evidence suggests the arising of possible emotions associated with disparities, unfairness, lack of trust and injustice, as the ability of individuals to perceive SWB variability rather than its average level among peers. As consequence, people tend to behave less materialistically, taking on sustainable (McDonald et al. 2006) and anticonsumption attitudes (Whitmarsh et al. 2017). The effect of living in a consumer society, 
Table 3 Robustness Check

\begin{tabular}{|c|c|c|c|}
\hline Ln_Expenditure & Ref1 & Ref2 & Ref3 \\
\hline Ln(EconSatisf) & $0.41 * * *$ & $1.06 * * *$ & $0.74 * * *$ \\
\hline Ln(SocSatisf) & 0.19 & $0.33 *$ & 0.30 \\
\hline Econ_Ref & $0.71 * * *$ & $0.62 * * *$ & $0.60 * * *$ \\
\hline Satisf_Ref & -0.05 & 0.04 & 0.02 \\
\hline Econ_Ineq & $0.93 * * *$ & $0.53 * * *$ & $0.28 * * *$ \\
\hline Satisf_Ineq & $-0.69 * *$ & 0.95 & $-0.52 * *$ \\
\hline Res_Ln(EconSatisf) & $-0.29 * *$ & $-0.94 * * *$ & $-0.62 * * *$ \\
\hline Res_Ln(SocSatisf) & -0.17 & -0.28 & -0.26 \\
\hline Young & $-0.11 * * *$ & $-0.04 * *$ & $-0.04 * *$ \\
\hline Middle-Aged & $-0.09 * * *$ & $-0.06 * * *$ & $-0.05 * * *$ \\
\hline Senior & $-0.02 *$ & $-0.08 * * *$ & $-0.05 * * *$ \\
\hline Gender & $-0.03 * * *$ & $-0.04 * * *$ & $-0.04 * * *$ \\
\hline HighEdu & -0.03 & $0.05 * *$ & $0.08 * * *$ \\
\hline Married & $0.02 *$ & $-0.02 *$ & $0.01 *$ \\
\hline Divorced & $0.13 * * *$ & $0.22 * * *$ & $0.17 * * *$ \\
\hline Widowed & $0.06 * * *$ & $0.05 * * *$ & $0.06 * * *$ \\
\hline Unemployed & $-0.06 * *$ & $0.07 * *$ & 0.03 \\
\hline Retired & $0.03 * * *$ & $0.02 * *$ & $-0.02 *$ \\
\hline Poor & $-0.72 * * *$ & $-0.54 * * *$ & $-0.61 * * *$ \\
\hline North & $0.02 *$ & 0.02 & $0.03 * *$ \\
\hline South & $0.09 * * *$ & $0.13 * * *$ & $0.09 * * *$ \\
\hline Rural & $-0.02 * *$ & $-0.03 * * *$ & $-0.04 * * *$ \\
\hline Metropolis & -0.01 & $-0.04 * * *$ & $0.04 * * *$ \\
\hline Constant & $1.74 * * *$ & $1.69 * * *$ & $2.22 * * *$ \\
\hline
\end{tabular}

$(* * *: p$-value $\leq 0.01 ; * *: \leq 0.05 ; *: \leq 0.1)$

characterised by high levels of perceived well-being inequality underlies social-psychological stress and failure in the achievement of a sense of authenticity, generating the selfreduction of expenditure levels as a voluntary action, as a result of a process of self-inquiry (Zavestoski 2002).

Taking into consideration the socio-demographic characteristics and the other controls included in the model, estimates confirm general empirical results shown by the economics of happiness and behavioural expenditure literature (Clark 2018; Guven 2012; Zhu et al. 2020). People's expenditure tends to increase at the highest levels of education, since it is one of the main determinants of improvement in consumer earnings and spending capability (Xiao 2015). Divorcees tend to spend more than the other categories, while Married is not significantly different from zero in every estimated model. Economic vulnerable conditions such as being poor and being unemployed have a significant and negative impact on expenditure, as risk-averse categories, while being retired appears to positively affect individuals' spending decisions. In line with findings reported by González (2011), people living in Northern Italy show higher expenditure levels than those living in the South. Moreover, people living in rural areas spend less money than people living in urban areas, while individuals living in a metropolis spend more money compared to people living in other urbanised areas of Italy. 


\subsection{Robustness checks}

Among the possible motivations for the strong heterogeneity in magnitudes and signs of the impact of relative measures and inequalities on individuals' utility, the identification of the reference norm and the aspect of inequality that is perceived by people are fundamental (Stephany 2017; Reyes-García et al. 2019). Thus, we evaluate the robustness of the estimates of Eq. 2 (M5 in Table 2) with respect to different definitions of the reference norm. In particular, we identify the reference groups considering three further categorizations, in line with the set of possible characteristics of social comparison identified by Ferrer-i-Carbonell (2005). In the first one (Refl) we consider region, urbanisation and education levels, defined as a four-levels categorical variable (identifying primary and secondary education, high school education and degree). The second categorisation (Ref2) takes the five-levels Italian macro-areas classification (i.e. North-East, North-West, Centre, South and Islands), the urbanisation level and age classes into account. Finally, the third classification (Ref3) considers the 20 Italian regions, the occupational sectors of economic activity of individuals as a categorical variable with three levels (i.e. primary, secondary and tertiary sector) and age classes.

Comparing the estimated coefficients in Table 3 with M5 in Table 2, it can be noticed that there are few differences concerning both self-perceived satisfaction scores in Refl and Ref3 and perceived satisfaction inequality for the social sphere in $\operatorname{Ref} 2$ with respect to M5. In particular, when the educational level of individuals is taken into account (Refl) instead of age and when the occupational sector of activity of individuals is considered instead of urbanisation (Ref3), the coefficient related to satisfaction with the social sphere turns out to be not significantly different from zero and the one related to satisfaction with the economic sphere is lower in magnitude in Refl (0.41) and in Ref3 (0.74) compared to M5 (1.05). Conversely, considering Italian macro-areas instead of regions in defining the reference norm (Ref2), the most striking difference with M5 concerns life satisfaction inequality that appears to be not relevant in affecting consumption expenditure levels in favour of a stronger impact of expenditure inequalities (0.54).

\section{Conclusion}

This study concentrates on the investigation of emotionality features in the expenditure consumption behaviours of individuals. Specifically, we investigate the role of self-perceptions and perceptions of peers in affecting individual expenditure, providing further insights about the role of these two emotional facets. Indeed, despite the relevance of both sources of emotionality in the analysis of individuals spending habits, at our knowledge no studies have yet considered these two topics simultaneously.

In particular, using Italian data about individuals' expenditures and satisfaction for the year 2016, two mains hypothesis have been tested. First, the possibility that expenditure behaviours may be related both to the felling of own well-being and to the comparison with peers, when the latter dimension is evaluated both through average level of the reference norm and through inequality. Close to this aim, we define and test a second hypothesis, concerning the presence of more than one source of perception of others. Specifically, we follow Attanasio and Pistaferri (2016), investigating perception of peers in the final goals of people's lives, i.e. considering consumption expenditure and satisfaction. This twofold 
reading of the reference group's utility has never been considered together in the analysis of agent's decision processes.

In order to test these (concatenated) hypotheses, we combine various life satisfaction scores to construct two measures of well-being, one related to satisfaction with economic conditions and the other with satisfaction with the social aspects of life, while perception of others is obtained considering the average level of SWB/expenditure in social reference group (each time excluding the specific individual), and the Gini inequality index.

Results demonstrate a high level of responsiveness of individuals to both SWB metrics and perception of others (H1). Differentiating among the two sources of social comparison (i.e. perceived SWB and consumption expenditure), we find empirical evidence of a bifold and opposite effect of perception of peers' utility on individual expenditure behaviour (H2). In particular, elasticities of expenditure related to economic aspects suggest a sensitivity closely related to perceived materialism. On the other hand, individuals seem to be not affected or not able to detect the true levels of satisfaction of their reference group, but they seem to be more aware and sensitive to satisfaction inequalities, as measure of injustice, unfairness, discrimination and inequity. Indeed, the estimates associated with well-being inequalities have a higher, significant and opposite effect on individual consumption expenditure, as result of a possible negative connection between consumerism and emotion-related goals about social aspects of life, such as "fun and enjoyment" and "family time" (Richins and Dawson 1992; Charles and Carstensen 2007).

Therefore, to stimulate consumption expenditure it is fundamental for policy makers to mitigate SWB disparities through the implementation of sets of actions targeting different age classes and geographical features such as urbanisation levels and regions of residence (Bernini and Tampieri 2019; 2020). The heterogeneity observed in these three dimensions in the analysis of the role of emotionality and perceptions in affecting expenditure is representative of cultural and contextual dissimilarities that distinguish Italy (Capello 2016). Indeed, if in rural and urban areas of Central-Southern Italy SWB inequalities appear to mostly affect people over 45, in metropolises located in Northern Italy young individuals are the most sensitive citizens. Moreover, in line with our findings about the economic sphere, policy makers should concentrate on actions with the goal of reducing individual vulnerability related to labour market conditions, such as youth unemployment and precarious working conditions.

Among the limits and further developments of this analysis, we will consider the investigation of the behavioural spending habits with respect to meaningful expenditure aggregates, i.e. distinguishing between basic consumption, luxury goods, durable and non-durable goods (Aguiar and Bils 2015). Similarly, a panel investigation can reveal fundamental variations in individual expenditure behaviours, depicting possible changes in the habits and sensitivity of individuals over time.

\section{Appendix 1}

The dataset has been built for 2016 considering two different Italian surveys, both developed by the Italian Office of Statistics (ISTAT): Aspect of Daily Life (ADL) and Household Budget Survey (HBS). Since the surveys refer to two different samples of individuals, the used data fusion procedure is taken from the statistical matching class of techniques (D'Orazio et al., 2006), and specifically from the micro non-parametric 
set of procedures. Thus, we aim to combine the information disjointly collected by ISTAT, using common variables in the two datasets. Operatively, we impute the ADL information about satisfaction scores in HBS, accounting for the distance between individuals. These measures of dissimilarities are calculated on the so-called matching variables, chosen among the common information. The procedure employed in this study, well-known as distance hot deck method (Okner, 1972), is refined considering (i) imputation without replacement, and (ii) referring to several donor classes, i.e. restricting the imputation from a specific donor record to a recipient one with the same gender and living in the same macro areas (North, Centre and South of Italy).

Appendix 1 presents the results of Bhattacharyya coefficient, Hellinger distance, total variation distance and the overlap between the two distributions (D'Orazio et al. 2006), for the imputed target variables (overall and life domains satisfaction). The

Table 4 Comparison of marginal distributions from statistical matching procedure

\begin{tabular}{lllll}
\hline & Battacharyya & Hellinger & Tvd & Overlap \\
\hline Sat & 0.999997 & 0.001686 & 0.001849 & 0.998151 \\
SatEco & 0.999999 & 0.000609 & 0.000525 & 0.999475 \\
SatEnv & 0.999999 & 0.000808 & 0.000874 & 0.999126 \\
SatRel & 0.999999 & 0.000915 & 0.001090 & 0.998910 \\
SatFri & 0.999996 & 0.001997 & 0.001890 & 0.998110 \\
SatHea & 0.999975 & 0.004984 & 0.005001 & 0.994999 \\
SatTim & 0.999998 & 0.001411 & 0.003937 & 0.998879 \\
\hline
\end{tabular}

Sat: Life Satisfaction, 1-10, from "Very Dissatisfied" to "Very Satisfied"

SatEco: economic condition; SatEnv: environmental condition; SatRel: relationships with relatives; SatFri: relationship with friends; SatTim: leisure time; SatHea: health condition: 1-4, from "Very Dissatisfied" to "Very Satisfied"

Tvd: Total Variation Distance

\begin{tabular}{llllll}
\hline & \multicolumn{2}{l}{ Donor (ADL) } & & \multicolumn{2}{l}{ Synthetic File } \\
\cline { 2 - 3 } \cline { 5 - 6 } & mean & sd & & mean & sd \\
\hline Gender & 0.53 & $(0.50)$ & & 0.64 & $(0.48)$ \\
Young & 0.12 & $(0.27)$ & & 0.28 & $(0.45)$ \\
Middle-Aged & 0.23 & $(0.45)$ & & 0.18 & $(0.39)$ \\
Adult & 0.32 & $(0.44)$ & & 0.26 & $(0.37)$ \\
Senior & 0.37 & $(0.48)$ & & 0.37 & $(0.48)$ \\
Unemployed & 0.11 & $(0.31)$ & & 0.13 & $(0.34)$ \\
Retired & 0.22 & $(0.42)$ & & 0.23 & $(0.42)$ \\
North & 0.42 & $(0.49)$ & & 0.43 & $(0.49)$ \\
Centre & 0.18 & $(0.38)$ & 0.18 & $(0.38)$ \\
South & 0.40 & $(0.49)$ & 0.39 & $(0.49)$ \\
Life Satisfaction & 7.03 & $(1.66)$ & 7.03 & $(1.58)$ \\
Total expenditure & - & - & 1452.11 & $(865.63)$ \\
\hline
\end{tabular}

Table 5 Descriptive Statistics 
values shown in the Table 4 confirm the good representativeness of the final synthetic dataset and the strong preservation of distributions of imputed variables.

Table 5 shows several descriptive statistics for the ADL sample, as donor dataset, and for the synthetic file obtained through the statistical matching, providing several insights about the preservation of marginal distributions for each variable imputed from the donor dataset to the recipient. Referring to the final dataset, the mean satisfaction score is 7.03 , whereas the mean total expenditure is $€ 1,452.11$.

\section{Appendix 2}

Once assumed that the satisfaction domains variables Economic conditions, AvailableInc, PreviousInc, Friends, Leisure and Health are ordered measurements of an underlying continuum, a factor analysis is performed using a polychoric correlation matrix (Table 6). The maximum likelihood solution given by Table7, provides two factors with associated eigenvalue greater than 1, explaining more than $85 \%$ of total variance. The final solution and the rotated loadings in Tables8, 9, 10 confirm the evidence of two resulting latent factors: Factor1, in the paper reported as the variable EconSatisf, and defined through the satisfaction domains mainly related to economic and material wellbeing (Economic conditions, AvailableInc, PreviousInc); and Factor2, in the paper identified by SocSatisf, extracted from the domains referring to relationships with friends (Friends), satisfaction with leisure time (Leisure) and health conditions (Health).

Table 6 Polychoric correlation matrix

\begin{tabular}{lllllll}
\hline & $\begin{array}{l}\text { Economic } \\
\text { conditions }\end{array}$ & AvailableInc & PreviousInc & Friends & Leisure & Health \\
\hline Economic conditions & 1.000 & & & & & \\
AvailableInc & 0.532 & 1.000 & & & & \\
PreviousInc & 0.389 & 0.563 & 1.000 & & & \\
Friends & 0.260 & 0.150 & 0.112 & 0.000 & 1.000 \\
Leisure & 0.306 & 0.166 & 0.121 & 0.386 & 0.376 \\
Health & 0.312 & 0.178 & 0.151 & 0.407 & & 1.000 \\
\hline
\end{tabular}

Table 7 Factor analysis: Maximum likelihood solution

\begin{tabular}{lllll}
\hline & Eigenvalue & Difference & Proportion & Cumulative \\
\hline Factor1 & 1.458 & -0.033 & 0.423 & 0.423 \\
Factor2 & 1.491 & 0.996 & 0.433 & 0.856 \\
Factor3 & 0.495 & & 0.144 & 1.000 \\
\hline
\end{tabular}

LR test: independent vs. saturated: $\operatorname{chi} 2(15)=3.0 \mathrm{e}+04$ Prob $>$ chi $2=0.000$

Log likelihood $=-0.0111$

Schwarz's (BIC) information criterion $=150.672$

Akaike's information criterion $=30.022$ 
Table 8 Maximum likelihood solution with number of factors equal two

\begin{tabular}{lllll}
\hline & Variance & Difference & Proportion & Cumulative \\
\hline Factor1 & 1.555 & 0.299 & 0.553 & 0.553 \\
Factor2 & 1.256 & & 0.447 & 1.000 \\
\hline
\end{tabular}

LR test: independent vs. saturated: $\operatorname{chi} 2(15)=3.0 \mathrm{e}+04$ Prob $>$ chi $2=0.0000$

LR test: 2 factors vs. saturated: $\operatorname{chi} 2(4)=89.51$ Prob $>\operatorname{chi} 2=0.0000$ Log likelihood $=-44.76136$

Schwarz's (BIC) information criterion $=199.999$

Akaike's information criterion $=111.523$

\begin{tabular}{llll}
\hline & Factor1 & Factor2 & Uniqueness \\
\hline Economic conditions & 0.575 & 0.354 & 0.544 \\
AvailableInc & 0.876 & 0.081 & 0.226 \\
PreviousInc & 0.636 & 0.072 & 0.591 \\
Friends & 0.108 & 0.618 & 0.606 \\
Leisure & 0.137 & 0.595 & 0.628 \\
Health & 0.151 & 0.619 & 0.595 \\
\hline
\end{tabular}

Table 9 Rotated factor loadings (pattern matrix) and unique variances

Table 10 Factor rotation matrix

\begin{tabular}{lcc}
\hline & Factor1 & Factor2 \\
\hline Factor1 & 0.937 & 0.350 \\
Factor2 & -0.350 & 0.937 \\
\hline
\end{tabular}

\section{Appendix 3}

Table 11 shows the estimates of the first stage of 2SLS procedure. The residuals obtained are finally included in the estimation of the model for the analysis of individual expenditures. In particular, for economic satisfaction we consider the presence of green areas in the neighbourhood of individual residence as instrumental variable, while the model for satisfaction with social aspects of life includes the number of hospitalizations and accesses to health care facilities, capturing health condition of individuals. 
Table 11 First stage estimates

\begin{tabular}{lcc}
\hline & EconSatisf & SocSatisf \\
\hline Young & $0.04^{* * *}$ & $0.05^{* * *}$ \\
Middle-Aged & $0.02^{*}$ & $0.04^{* * *}$ \\
Senior & $0.05^{* * *}$ & $-0.01^{*}$ \\
Gender & 0.01 & 0.00 \\
HighEdu & 0.16 & 0.03 \\
Married & 0.02 & 0.00 \\
Divorced & -0.14 & -0.03 \\
Widowed & -0.06 & -0.04 \\
Unemployed & -0.20 & 0.00 \\
Retired & 0.03 & 0.00 \\
Poor & -0.38 & -0.02 \\
North & 0.01 & 0.03 \\
South & -0.08 & -0.03 \\
Rural & 0.03 & 0.00 \\
Metropolis & 0.06 & 0.00 \\
Instrument & 0.05 & -0.07 \\
Constant & 0.35 & 1.01 \\
\hline
\end{tabular}

Funding No funding was received for conducting this study.

Open Access This article is licensed under a Creative Commons Attribution 4.0 International License, which permits use, sharing, adaptation, distribution and reproduction in any medium or format, as long as you give appropriate credit to the original author(s) and the source, provide a link to the Creative Commons licence, and indicate if changes were made. The images or other third party material in this article are included in the article's Creative Commons licence, unless indicated otherwise in a credit line to the material. If material is not included in the article's Creative Commons licence and your intended use is not permitted by statutory regulation or exceeds the permitted use, you will need to obtain permission directly from the copyright holder. To view a copy of this licence, visit http://creativecommons.org/licenses/by/4.0/.

\section{References}

Aguiar, M., Bils, M.: Has consumption inequality mirrored income inequality? Am. Econ. Rev. 105(9), 2725-2756 (2015)

Alesina, A., Di Tella, R., MacCulloch, R.: Inequality and happiness: are Europeans and Americans different? J. Public Econ. 88, 2009-2042 (2004)

Attanasio, O.P., Pistaferri, L.: Consumption inequality. J. Econ. Perspect. 30(2), 3-28 (2016)

Bernini, C., Tampieri, A.: Happiness in Italian cities. Reg. Stud. 53(11), 1614-1624 (2019)

Bernini, C., Emili, S., Galli, F.: Does urbanisation matter in the expenditure-happiness nexus? Pap. Reg. Sci. 100(6), 1403-1428 (2021)

Bernini, C., \& Tampieri, A. (2020) The mediating role of urbanisation on the composition of happiness. Working Papers - Economics wp2020_16.rdf, Universita' degli Studi di Firenze, Dipartimento di Scienze per l'Economia e l'Impresa.

Blanchflower, D., Oswald, A.: Does inequality reduce happiness? Evidence from the states of the USA from the 1970s to the 1990s. Warwick University, Mimeographed (2003)

Blanchflower, D., Oswald, A.: Is well-being U-shaped over the life cycle? Soc. Sci. Med. 66, 1733-1749 (2008)

Blundell, R., Browning, M., Meghir, C.: Consumer demand and the life-cycle allocation of household expenditures. Rev. Econ. Stud. 61(1), 57-80 (1994) 
Boehm, J.K., Lyubomirsky, S.: Does happiness promote career success? J. Career Assess. 16(1), 101116 (2008)

Bowles, S., Park, Y.: Emulation, inequality, and work hours: was thorsten veblen right? Econ. J. 115(507), F397-F412 (2005)

Brodeur, A., Fleche, S.: Neighbors' income, public goods, and well-being. Rev. Income Wealth 65(2), 217-238 (2019)

Bronner, S.: Consuming visions: accumulation and display of goods in America, 1880-1920. Norton, New York, NY (1989)

Capello, R.: What makes Southern Italy still lagging behind? A diachronic perspective of theories and approaches. Eur. Plan. Stud. 24(4), 668-686 (2016)

Carbonaro, G. (1985) Nota Sulla Scale di Equivalenza. In La Povertà in Italia, Presidenza del Consiglio dei Ministri, Istituto Poligrafico dello Stato, Rome.

Carver, T., Grimes, A.: Income or consumption: which better predicts subjective well-being? Rev. Income Wealth 65(S1), 256-280 (2019)

Chai, A., Kaus, W., Kiedaisch, C.: Conspicuous spending and the income distribution of social groups. Econ. Inq. 57(3), 1324-1341 (2019)

Charles, S.T., Carstensen, L.L.: Emotion regulation and aging. In: Gross, J.J. (ed.) Handbook of emotion regulation, pp. 307-327. Guilford Press, New York (2007)

Clark, A.E.: Unemployment as a social norm: psychological evidence from panel data. J. Law Econ. 21(2), 289-322 (2003)

Clark, A.E.: Happiness, income and poverty. Int. Rev. Econ. 64(2), 145-158 (2017)

Clark, A.E.: Four decades of the economics of happiness: where next? Rev. Income Wealth 64(2), 245269 (2018)

Clark, A.E., Oswald, A.J.: Satisfaction and comparison income. J. Public Econ. 61, 359-381 (1996)

Clark A.E., Frijters, P., \& Schields M.A. (2008) Relative Income, Happiness, and Utility: An Explanation for the Easterlin Paradox and Other Puzzles. J. Econ. Lit. 46(1), 95-144

D’Orazio, M., Di Zio M., \& Scanu M. (2006) Statistical matching, theory and practice. Wiley, New York.

De Neve, J.E., Oswald, A.J.: Estimating the influence of life satisfaction and positive affect on later income using sibling fixed effects. Proc. Natl. Acad. Sci. u.s.a. 109(49), 19953-19958 (2012)

De Neve, J. E., Diener, E., Tay, L., \& Xuereb, C. (2013) The objective benefits of subjective well-being. CEP Discussion Paper No 1236.

De Prophetis, E., Goel, V., Watson, T., Rosella, L.: Relationship between life satisfaction and preventable hospitalisations: a population-based cohort study in Ontario Canada. Epidemiology 10, e032837 (2020). https://doi.org/10.1136/bmjopen-2019-032837

Decancq, K., Fleurbaey, M., Schokkaert, E.: Inequality, income, and well-being. In: Atkinson, A.B., Bourguignon, F. (eds.) Handbook on income distribution, vol. 2, pp. 67-140. Elsevier, Amsterdam (2015)

DeLeire, T., \& Kalil, A. (2010) Does consumption buy happiness? Evidence from the United States. Int. Rev. Econ. https://doi.org/10.1007/s12232-010-0093-6

Di Tella, R., MacCulloch, R.: Gross national happiness as an answer to the Easterlin Paradox? J. Dev. Econ. 86(1), 22-42 (2008)

Diener, E., Oishi, S., Lucas, R.E.: National accounts of subjective well-being. Am. Psychol. 70(3), 234242 (2015)

Easterlin, R. A., \& Sawangfa, O. (2007) Happiness and domain satisfaction: theory and evidence. IZA Discussion Papers from Institute of Labor Economics, No 2584.

Fernández-Villaverde, J., Krueger, D.: Consumption over the life cycle: some facts from consumer expenditure survey data. Rev. Econ. Stat. 89(3), 552-565 (2007)

Ferrer-i-Carbonell, A.: Income and well-being: an empirical analysis of the comparison income effect. J. Public Econ. 89, 997-1019 (2005)

Foner, A. (1988) Age inequality. Are they epiphenomena of the class system? In: American Sociological Association presidential series. Social change and the life course, Vol. 1. Social structures \& human lives (p. 176-191). Sage Publications, Inc.

Foy, S., Freeland, R., Miles, A., Rogers, K.B., Smith-Lovin, L.: Emotions and affect as source, outcome and resistance to inequality. In: McLeod, J., Lawler, E., Schwalbe, M. (eds.) Handbook of the social psychology of inequality, pp. 295-324. Handbooks of Sociology and Social Research, Springer, Dordrecht (2014)

Geyskens, I., Steenkamp, J.B.E.M.: Economic and social satisfaction: measurement and relevance to marketing channel relationships. J. Retail. 76(1), 11-32 (2000)

Giarda, E., Moroni, G.: The degree of poverty persistence and the role of regional disparities in italy in comparison with France, Spain and the UK. Soc. Indic. Res. 136(1), 163-202 (2018) 
González, S.: The North/South divide in Italy and England: discursive construction of regional inequality. Euro. Urban Reg. Stud. 18(1), 62-76 (2011)

Graafland, J., Lous, B.: Income inequality, life satisfaction inequality and trust: a cross country panel analysis. J. Happiness Stud. 20, 1717-1737 (2019)

Graham, C., Felton, A.: Inequality and happiness: insights from Latin America. J. Econ. Inequal. 4, 107122 (2006)

Graham, C., Eggers, A., Sukhtankar, S.: Does happiness pay? An exploration based on panel data from Russia. J. Econ. Behav. Organ. 55(3), 319-342 (2004)

Guillen-Royo, M.: Consumption and subjective wellbeing: exploring basic needs, social comparison, social integration and hedonism in peru. Soc. Indic. Res. 89, 535-555 (2008)

Guven, C.: Are happier people better citizens? Kyklos (2011). https://doi.org/10.1111/j.1467-6435.2011. 00501.x

Guven, C.: Reversing the question: does happiness affect consumption and savings behavior? J. Econ. Psychol. 33(4), 701-717 (2012)

Harriger-Lin, J., Khanna, N., Pape, A.: Conspicuous consumption and peer-group inequality: the role of preferences. J Econ. Inequal. 18, 365-389 (2020)

Heathcote, J., Perri, F., Violante, G.L.: Unequal we stand: an empirical analysis of economic inequality in the United States, 1967-2006. Rev. Econ. Dyn. 13(1), 15-51 (2010)

Helliwell, J.F.: How's life? Combining individual and national variables to explain subjective well- being. Econ. Model. 20, 331-360 (2003)

Helliwell, J., Layard, R., Sachs, J.: World happiness report. UN Sustainable Development Solutions Network, New York (2013)

Helne, T., Hirvilammi, T.: Wellbeing and sustainability: a relational approach. Sustain. Dev. 23, $167-175$ (2015)

Hopwood, B., Mellor, M., O’Brien, G.: Sustainable development: mapping different approaches. Sustain. Dev. 13, 38-52 (2005)

Istat (2015) Rapporto Annuale 2015. https://www.istat.it/it/files/2015/05/Rapporto-Annuale-2015.pdf

Kahneman, D., Krueger, A.: Developments in the measurement of subjective well-being. J. Econ. Perspect. 20, 3-24 (2006)

Kalmijn, W., Veenhoven, R.: Measuring inequality of happiness in nations: in search for proper statistics. J. Happiness Stud. 6, 357-396 (2005)

Krause, A.: Don't worry, be happy? Happiness and reemployment. J. Econ. Behav. Organ. 96, 1-20 (2013)

Lam, K.C.J., Liu, P.W.: Socio-economic inequalities in happiness in china and US. Soc. Indic. Res. 116(2), 509-533 (2014)

Laros, F.J.M., Steenkamp, J.B.E.M.: Emotions in consumer behavior: a hierarchical approach. J. Bus. Res. 58, 1437-1445 (2005)

Lenzi, C., Perucca, G.: Are urbanized areas source of life satisfaction? Evidence from EU regions. Pap. Reg. Sci. 97, S105-S122 (2018)

Luttmer, E.: Neighbors as negatives: relative earnings and well-being. Quart. J. Econ. 120, 963-1002 (2005)

Lyubomirsky, S., Sheldon, K.M., Schkade, D.: Pursuing happiness: the architecture of sustainable change. Rev. Gen. Psychol. 9(2), 111-131 (2005)

Mace, G.M.: Whose conservation? Science 345, 1558-1560 (2014)

McDonald, S., Oates, C.J., Young, C.W., Hwang, K.: Toward sustainable consumption: researching voluntary simplifiers. Psychol. Mark. 23(6), 515-534 (2006)

Meyer, B.D., Sullivan, J.X.: Consumption and income inequality in the U.S. since the 1960s. Am. Econ. Rev. 103(3), 178-183 (2013)

Odoardi, I., Muratore, F.: The Italian regional dualism: a MARS and panel data analysis. Rev. Reg. Stud. 48(3), 323-346 (2018)

Okner, B.A.: Constructing a new data base from existing microdata sets: the 1966 merge file. J. Econ. Soc. Meas. 1(3), 325-342 (1972)

Okulicz-Kozaryn, A., Mazelis, J.M.: More unequal in income, more unequal in wellbeing. Soc. Indic. Res. 132, 953-975 (2017)

Oshio, T., Kobayashi, M.: Area-level income inequality and individual happiness: evidence from Japan. J. Happiness Stud. 12, 633-649 (2011)

Oswald, A., Proto, E., Sgroi, D.: Happiness and productivity. J. Law Econ. 33, 789-822 (2015)

Reyes-García, V., Angelsen, A., Shively, G.E., Minkin, D.: Does income inequality influence subjective wellbeing? Evidence from 21 developing countries. J. Happiness Stud. 20, 1197-1215 (2019)

Richins, M.L., Dawson, S.: A consumer values orientation for materialism and its measurement: scale development and validation. J. Consum Res 19, 303-316 (1992)

Ridder, G., \& Moffitt, R. (2007) The econometrics of data combination. In: Heckman, J.J., Leamer, E.E. (Eds.), Handbook of Econometrics, Vol. 6, Part B (Chapter 75). Elsevier, Amsterdam, 5469-5547. 
Roychowdhury, P.: Visible inequality, status competition, and conspicuous consumption: evidence from rural India. Oxf. Econ. Pap. 69, 36-54 (2017)

Schoemaker, P.: Determinants of risk taking: behavioural and economic views. J. Risk Uncertain. 6, 493$501(1993)$

Seeley, E.: Human needs and consumer economics: the implications of maslow's theory of motivation for consumer expenditure patterns. J. Socio-Econ. 21(4), 303-324 (1992)

Solnick, S., Hemenway, D.: Are positional concerns stronger in some domains than in others? Am. Econ. Rev. 95, 147-151 (2005)

Stephany, F.: Who are your joneses? socio-specific income inequality and trust. Soc. Indic. Res. 134, 877898 (2017). https://doi.org/10.1007/s11205-016-1460-9

Sumarwan, U.: Riset pemasaran dan Konsumen Seri 1. IPB Press, Bogor (ID) (2011)

Tavor, T., Gonen, L.D., Weber, M., Spiegel, U.: The Effects of Income Levels and Income Inequalities on Happiness. J. Happiness Stud. 19(7), 2115-2137 (2018)

Tilman, R. (1992) Thorstein veblen and his critics. Princeton University Press (N.J.), 1891-1963.

Tversky, A., Kahneman, D.: Loss aversion in riskless choice: a reference-dependent model. Q. J. Econ. 106(4), 1039-1061 (1991)

Van Praag, B., Ferrer-i-Carbonell, A.: Inequality and Happiness. In: Salverda, W.G., Nolan, B., Smeeding, T.M. (eds.) The oxford handbook of economic inequality, pp. 364-383. Oxford University Press, Oxford (2011)

Veblen, T.: The theory of the leisure class. Macmillan, New York, NY (1899)

Veenhoven, R. (1990) Inequality in happiness, inequality in countries compared between countries. Working Group Social Indicators and Quality of Life. Session 7, Social Trends and Inequality.

Verme, P.: Life satisfaction and income inequality. Rev. Income Wealth 57, 111-137 (2011)

Walsh, L.C., Boehm, J.K., Lyubomirsky, S.: Does Happiness Promote Career Success? Revisiting the Evidence. J. Career Assess. 26(2), 199-219 (2018)

Ward, S.J., King, L.A.: Poor but happy? Income, happiness, and experienced and expected meaning in life. Soc. Psychol. Person. Sci. 7(5), 463-470 (2016)

Western, M., Tomaszewski, W.: Subjective wellbeing, objective wellbeing and inequality in Australia. PLoS ONE (2016). https://doi.org/10.1371/journal.pone.0163345

Whitmarsh, L., Capstick, S., Nash, N.: Who is reducing their material consumption and why? A crosscultural analysis of dematerialization behaviours. Philos. Trans. Royal Soc. A 375, 20160376 (2017). https://doi.org/10.1098/rsta.2016.0376

Xiao, J.J.: Consumer economic wellbeing. Springer, New York, NY (2015)

Yeniaras, V., Akkemik, K.A., Yucel, E.: Re-considering the linkage between the antecedents and consequences of happiness. J. Econ. Psychol. 56, 176-191 (2016)

Zavestoski, S.: The social-psychological bases of anticonsumption attitudes. Psychol. Mark. 19(2), 149-165 (2002)

Zhu, Z., Ma, W., Leng, C., Nie, P.: The relationship between happiness and consumption expenditure: evidence from rural China. Appl. Res. Qual. Life (2020). https://doi.org/10.1007/s11482-020-09836-z

Publisher's Note Springer Nature remains neutral with regard to jurisdictional claims in published maps and institutional affiliations. 